\title{
Applying Values-Engaged Approach to Evaluate the Impact of Self-Regulated Strategy Development Writing Program
}

\author{
Su-Ching Lin \\ Graduate Institute of Education, National Changhua University of Education \\ 1, Jin De Road, Paisha Village, Changhua, 50007, Taiwan \\ Tel: 886-4723-2105\# 2234 E-mail: sclin@cc.ncue.edu.tw
}

Ming-Sui Wu

Dept. of Applied Japanese, Ming-Chuan University, Taiwan

5, De Ming Rd.,Gui Shan District, Taoyuan City, 333, Taiwan

Tel: 886-2-2882-4564Ｅ-mail:mswu@mail.mcu.edu.tw

Lin-Ye Tsai

Taichung Jhong Hua Elementary School, Taiwan

No. 2, Sec. 3, HanKou Road, Taichung City, 40441, Taiwan

Tel: 886-4-2297-9601Ｅ-mail: t0928110071@gmail.com

Received: Jan 29, 2018 Accepted: May 21, 2018 Published: May 21, 2018

doi:10.5296/jse.v8i2.12557 URL: https://doi.org/10.5296/jse.v8i2.12557

\begin{abstract}
This case study aimed to apply the values-engaged approach to evaluate the impact of the Self-Regulated Strategy Development writing program (SRSDP) on the Grade 5 students, including the application of writing self-regulated strategy, writing motivation, and writing performance. The participants consisted of 26 Grade 5 students from the same class. The SRSDP had been implemented for 12 weeks. During the research period, based on the core
\end{abstract}


perspective of values-engaged approach to evaluation, the researchers, particularly concerned with the experience and perception of those least well-served students. The data were collected through quantitative and qualitative approaches, composing of the Scales of Writing Self-Regulated Strategy, Writing Motivation, and Writing Performance, students' worksheets, feedback sheets, and group focused interview. Quantitative Data analyses included descriptive analysis and dependent sample $t$-test. Qualitative data analyses consisted of organizing data, coding data, and analyzing and interpreting data. The study found that SRSDP provided remarkable positive influences on lower-level and middle-level students' writing performance and their application of the application of writing self-regulated strategy. SRSDP also brought wonderful writing and learning experiences to the lower-level students. Based on the findings, the conclusion and discussion were also made in the study.

Keywords: Self-regulated strategy development program, values-engaged approach to evaluation, writing self-regulated strategy, writing performance, writing motivation 


\section{Introduction}

The major purpose of teaching writing is to cultivate students to integrate an expression, logic, organization, reflection, criticism, appreciation, and social awareness. Writing not only helps students in daily life and academic performance but also benefits them for workplace development in the future (Fitzgerald, 2013; Harris \& Graham, 2009). However, the findings of several studies conducted in Taiwan indicate that it is necessary to strengthen elementary schoolers' writing skills, such as purposive sampling, structure, diction, spelling, and formatting and punctuation (Gao, 2006; Xu \& Yang, 2010; Yang, 2006). The studies also pointed out, most of the elementary students' lack of background knowledge, writing skills, and writing motivation, which might result in their poor writing. Second, an instructor often stresses learning various kinds of rhetoric rather than on the rhetoric purpose or objects of writing themselves during teaching writing. Besides, he or she doesn't give individual students guidance based on their needs due to time limitation; therefore, the major factors contribute to students' poor writings might from instructors and students themselves.

Earlier writing instruction ignored writers' psychological inquiry so that its effectiveness was limited (Hillocks, 1984). Until Flower and Hayes (1981) introduced a theory of the cognitive processes of writing, which involved in three dimensions, including writing environment, long-term memory, and writing process composing of stages of planning, transcription, and reviewing, writers could develop self-regulated ability through peer editing or self-help (Hayes \& Flower, 1983). However, Brandt (1992) from a social perspective recommended an adaptation of Flower and Hayes' model should put much concern on the role of the social context and the social structure of individual acts of writing. Due to the criticism, Hayes (1996) has proposed the revision of his model. Hayes's model comprises the individual and task environment dimensions. Hayes has named it "an individual-environmental model". The individual dimension comprises of the writer's cognition, affection, and memory system. The second dimension is the environmental dimension referring to both the writer's social and physical environment. It concerns all the external factors that can influence the writer. Since the 1980s, teaching writing model, influenced by self-regulated learning (SRL) theory, created a new vision. SRL theory indicated that writing was a very complex process of self-regulation, in which the individuals not only adjusted their writing behaviors through self-observation, self-assessment, and self-learning process but also produced their own thoughts, feelings, and actions to achieve their learning goals through the process of metacognition and active participation (Zimmerman, 1986).

Harris and Graham (1996) developed the SRSD teaching model by integrating SRL theory and cognitive processes of writing. Six stages in the SRSD teaching model include developing background knowledge, discussing it, modeling it, memorizing it, supporting it, and independent performance. Along with the different stages of teaching, it transfers the writing responsibilities to the students (Graham, Harris, \& Mason, 2005). The most important goal of SRSD is to help students manage their thoughts, behaviors, and emotions in order to successfully navigate their learning experiences. This process occurs when a student's master cognitive and meta-cognitive strategies in writing task and develop the autonomous self-regulated use of the strategies (Campbell \& Campbell, 2009). This model was originally 
developed to teach writing skills to children and youth with learning disabilities (Harris, Graham, \& Mason, 2006). Because SRSD could effectively improve the performance of writing knowledge, writing methods, writing qualities, and writing efficacy for the disabled students, it has been very popular among the special education in the U.S. (Graham \& Harris, 2003, 2009). More recently, SRSD has also applied to the regular students in writing classes across all grade levels (Bakry \& Alsamadani, 2015; Festas, Oliveira, Rebelo, Damião, Harris, \& Graham, 2015; Harris, Graham, \& Adkins, 2015). Research indicates that SRSD for writing is effective with students who represent the full range of the writing ability in a typical elementary class. These studies proved that such teaching model not only benefited those special-need students, but also helped the regular students (Graham, McKeown, Kiuhara, \& Harris, 2012; Harris \& Graham, 2009).

The core work of program evaluation is based on a certain set of criteria to make a judgment about the merit or meaning of the program; therefore, it is characterized as a value-laden enterprise (Christie \& Alkin, 2008, Mabry, 2010). Describing stakeholders' values and using them as part of criteria to judge the merit of the program is the responsive tradition in the evaluation. In the responsive evaluation, the evaluator concerns of various stakeholders' values which were included in their descriptions of program experiences and the judgments of their meaningfulness and outcomes (Stake, 2004). The responsive evaluation grounded in a constructivist paradigm identifies that the meanings of program practices are created through participants' interpretations of interactions and dialogue. Further, those meanings stand for values that are constantly being bargaining in practice (Amba, 2006; Everitt, 1996). This view sets evaluation as a process in which evaluators should not only describe various values but also create opportunities for diverse stakeholders' views to be listened to (Guba \& Lincoln, 1989). However, House and Howe (1999) who advocated deliberative democratic evaluation indicated that societal inequalities existed in stakeholder's power and voice. Evaluators should particularly concern the voices of those who have been marginalized or excluded. House and Howe have recommended the principles of inclusion, dialogue, and deliberation as a guideline for stakeholder involvement in the evaluative process. These sensibilities bring in the prescriptive perspective on valuing in an evaluation. Prescriptive valuing is supported in the democratic evaluation tradition in which evaluation inevitably promotes certain values, such as social justice and equity. These two values are the most defensible values to promote (Greene, DeStefano, Burgon, \& Hall, 2006).

Values-engaged (VE) approach to program evaluation, which is grounded in both responsive and democratic traditions in explicitly and intentionally involves descriptions and prescriptions of values (Greene et al, 2006). In other words, evaluators do not only describe stakeholder's values but also prescribe certain values in this approach. VE approach describes equity has been concerned with the treatment of program stakeholders, specifically, how well the evaluand affords program access, meaningful participation, and accomplishment for all relevant stakeholders. Methodologically, being inclusive and creating opportunities for varied stakeholders' views to be heard can be enacted through generating evaluation questions, data, and dialogues related to the ways in which a program is attending appropriately and with meaningful consequence to all individuals and groups that 
are present in the context, particularly those least well served. The criteria for judging program quality include the advancement of the interests of underrepresented and underserved groups. That is, a good program is judged, in part, by how well it promotes the interests and accomplishments of those least well served (Hall, Ahn, \& Greene, 2012).

Base on the above, this case study attempted to apply VE approach to evaluate the impact of the self-regulated strategy development writing program (SRSDP) on writing performance, writing motivation, and the application of self-regulated strategy of three writing level students in a Grade 5 class, including lower level, middle level, and higher level. The criteria for judging program quality, particularly concerned the meaningful participation, and accomplishment for students with lower writing level. Therefore, this study not only reported the findings of quantitative results of the program impact on three-level students but also explored lower level students' program experience. The specific research questions in this study included: (1) Is there significant a difference between pre-test score and post-test score in writing performance scale for three-level students? (2) Is there a significant difference between pre-test score and post-test score in writing motivation scale for different three-level students? (3) Is there a significant difference between pre-test score and post-test score on the scale of self-regulated writing strategy for three-level students? (4) What are the experiences of lower level students toward SRSDP?

\section{Methodology}

\subsection{Program participants}

The program participants in this case study consisted of 26 Grade 5 students from the same class including 13 boys and 13 girls. All students were diagnosed by Writing Performance Scale to decide which writing level they belonged to in the before program implementation. Based on the result, 10 students were diagnosed with lower writing level, 10 students were middle writing level, and 6 students were higher writing level.

\subsection{The program design and impact evaluation}

The SRSDP composed of 6 units and implemented in 12 weeks. The teaching model of SRSDP covered six stages: developing background knowledge, discussing it, modeling it, memorizing it, supporting it, and independent performance, along with the different teaching stages, the instructor tried to transfer the writing responsibilities to the students. Firstly, the instructor introduced the process of writing, through a description of the importance of the writing strategies and self-regulated strategies (SRS) including self-instruction, goal-setting, self-monitoring, and self-reinforcement. Next, the instructor guided the students to discuss how to use these strategies. Secondly, the instructor took an example to demonstrate how to apply SRS during their writing processes. Thirdly, through discussion, each group attempted to use the SRS in completing mind mapping writing collaboratively. Fourthly, the instructor reviewed and modified group writings respectively. After that, the instructor guided the whole class to involve in sharing their experiences about using SRS in their writings. Fifthly, every student independently practiced SRS in his/her writing. At the same time, the instructor supported the students' strategic use and provided feedback on writing and self-regulation. 
The last stage is independent performance. Students used strategies of self-regulation in writing independently.

The impact evaluation of SRSDP focused on the students' application of the SRS, writing motivation, and writing performance. During the research period, based on the core value of values-engaged approach of evaluation, this study was particularly concerned with the experience and perception of those students with lower writing level. Program evaluative data collection and analysis not only focused on the impact on different writing levels but also were concerned about the impact on the individuals who were the lower writing level students.

\subsection{Data collection and analysis}

Three major quantitative instruments in this study were used in pre-test and post-test to assess the impact of the SRSDP on student writing performance, writing motivation, and the application of SRS in writing including Writing Performance Scale (WPS), Writing Motivation Scale (WMS), and Writing Self-Regulated Strategy Scale (WSRSS).

WPS developed by Center for Psychological and Educational Testing Research and Development (2013) with seven levels (from zero to sixth), was designed to assess the writing skills. It included four dimensions of writing skills, purposive sampling, structure, diction, and spelling, formatting, and punctuation. The inter-rater correction coefficient for these four dimensions ranged. 92, .91, .89, and.93. The overall inter-rater correction coefficient (.94) for the scale was therefore good.

WMS developed by Wang (2009) with 26 items was designed to assess the four dimensions, including writing interest, emotions, self-efficacy, and importance and utility. Participants were asked to rate the items on a four-point Likert scale anchoring at 1, 2, 3, and 4 (from strongly disagree to strongly agree). The factor analysis performed on the data obtained by WMS reveals that each item in all subscale dimensions produced factor loadings was $61.58 \%$. The overall internal consistency (Cronbach's $\alpha=.91$ ) for the scale was good. The Cronbach's $\alpha$ for the four subscales ranged from .85 to .93 , indicating good internal consistencies of the items within each subscale.

WSRSS developed by Jiang (2013) with 43 items was designed to assess five dimensions, including writing self-regulated cognition, motivation, emotion, behavior, and situation. Participants were asked to rate the items on a four-point Likert scale anchoring at 1, 2, 3, and 4 (from always to never). The factor analysis made on data obtained by WSRSS reveals that each item in all subscale dimensions produced factor loadings was $67.40 \%$. The overall internal consistency (Cronbach's $\alpha=.91$ ) for the scale was good. The Cronbach's $\alpha$ for the five subscales ranged from .48 to .84 , indicating good internal consistencies of the items within each subscale.

Quantitative data analysis was done using SPSS 20.0 for Windows. Results were analyzed using descriptive statistics in terms of distribution frequencies, mean values, and standard deviations, and dependent sampling t-test. In addition, data were collected through several qualitative approaches, such as focus group interview, students' feedback, and worksheets. 
Qualitative data analysis included organizing data, coding data, and analyzing and interpreting data; however, this study only described quantitative results and program feedbacks of lower writing level students collected from the data of focus group interview, worksheets, and feedback sheets.

\section{Findings}

\subsection{The impact of SRSDP on three-level students' writing performance}

Table 1 shows different analysis results of writing performance for three-level students at the overall dimension of WPS. The post-test mean scores of both of lower-level students $(t=3.25$, $p<.01)$ and middle-level students $(t=4.74, p<.001)$ are higher than those of pre-test.

Table 1. t-test of overall dimension of WPS for three-level students

\begin{tabular}{lllllc}
\hline & \multicolumn{3}{c}{ Pre-test } & \multicolumn{3}{c}{ Post-test } \\
\cline { 2 - 5 } Writing level & $M$ & $S D$ & $M$ & $S D$ & $t$ \\
\hline lower $(n=10)$ & 2.60 & 0.52 & 3.50 & 0.53 & $3.25^{* *}$ \\
middle $(n=10)$ & 3.60 & 0.52 & 4.60 & 0.52 & $4.74^{* * *}$ \\
higher $(n=6)$ & 5.00 & 0.00 & 5.17 & 0.00 & 1.00 \\
\hline
\end{tabular}

$* * p<.01 . * * * p<.001$.

Based on the above analysis, this study confirms that the SRSDP provides remarkable positive influences on both of lower-level and middle-level students' writing performance. VE approach for program evaluation deeply concerned equity with the treatment of program stakeholders, especially concerning the advancement of the interests of underrepresented and underserved groups. Hence, this study describes the meaningful participation, and accomplishment particularly for lower-level students via focus group interview and feedback sheets. Most of the lower-level students share their positive feeling to writing performance after attending SRSDP. For examples:

I used to hate writing class because I am really bad at writing. However, after I was taught by self-regulated strategy for writing, I know how to do my writing assignment. This makes me very happy and my writing performance is getting better (LGW feedback).

I used to be very bad at writing and even couldn't finish writing assignment alone, but this semester I learn writing skills from SRSDP. It is awesome! I got higher ranks in my writing assignment than before (LBZ feedback).

Writing used to be the last thing I want to do. However, this situation is changing. The teacher used an interesting method to teach us how to write, 
which make writing more interesting and the ranks of my writing assignment are getting higher (LBR feedback).

Except for students' feedback, the study also finds that lower-level students have been made a big progress in writing performance after attending SRSDP by comparing their pre-test writing assignments and post-testing writing assignments. Even though their writing quality is still not perfect yet, they really improve their writing a lot.

\subsection{The impact of the SRSDP on students' writing motivation}

Table 2 indicated that no significant difference found between three-level students' pre-test mean scores and post-test mean scores at the overall dimension of WMS.

Table 2. t-test of overall dimension of WMS for three-level students

\begin{tabular}{llllll}
\hline & \multicolumn{2}{c}{ Pre-test } & \multicolumn{3}{c}{ Post-test } \\
\cline { 2 - 5 } & $M$ & $S D$ & $M$ & $S D$ & $t$ \\
Writing level & & & & 1.96 \\
lower $(n=10)$ & 2.30 & 0.95 & 2.60 & 0.84 & 1.96 \\
middle $(n=10)$ & 2.80 & 0.92 & 3.10 & 0.74 & 1.00 \\
\hline
\end{tabular}

Based on the above analysis, this study confirms that the SRSDP do not provide significant influences on students' writing motivation. However, lower-level students pinpoint that SRSDP enhances their writing motivation during focus group interview. For example,

Originally, I really didn't like a writing class because It was boring. However, I have much fun in writing class now (LGS interview).

This writing class is different with the writing class before. The teacher asked each group to discuss and used self-regulated strategies in completing mind mapping writing collaboratively. I really enjoyed discussing and sharing ideas with my group (LGW interview).

I learned how to use self-regulated strategy in my writing assignment, which evoked my writing interest (LBJ interview).

\subsection{The impact of SRSDP on students' application of SRS in writing process}

Table 3 shows different analysis result of the application of SRS for three-level students at the overall dimension. The post-test mean scores of both lower-level students $(t=2.95, p<.01)$ and middle-level students $(t=4.89, p<.001)$ are significantly higher than those of pre-test. 
Table 3. t-test of overall dimension of SRS for three-level students

\begin{tabular}{llllll}
\hline & \multicolumn{3}{c}{ Pre-test } & \multicolumn{3}{c}{ Post-test } \\
\cline { 2 - 5 } Writing level & $M$ & $S D$ & $M$ & $S D$ & $t$ \\
\hline lower $(n=10)$ & 2.61 & 0.72 & 3.02 & 0.75 & $2.95^{*}$ \\
middle $(n=10)$ & 2.74 & 0.67 & 3.03 & 0.65 & $4.89^{* * *}$ \\
higher $(n=6)$ & 2.33 & 0.35 & 2.76 & 0.58 & 2.34 \\
\hline
\end{tabular}

$* p<.05 . * * * p<.001$

Based on the above analysis, this study confirms that the SRSDP provided remarkable positive influences on both of lower-level and middle-level students' application of writing self-regulated strategy. Besides, lower-level students explored that SRSDP enhanced their writing skills during focus group interview. For example,

After I learned self-regulated strategy, writing is getting easier than before.

This skill provided specific steps of writing to me. Then, I could use it to finish my writing assignment little by little. Now I don't worry about delaying to hand in my writing assignment, which is wonderful to me (LBQ interview).

I encountered many problems with my writing. I really appreciated that my teacher helped me to overcome them by teaching me the self-regulated strategy of writing. She also gave me guidance to resolve the problem. Literally, I could independently apply the self-regulated strategy in my writing process, which gave much accomplishment to me (LBE interview).

For me, the self-regulated strategy is new skills. I never heard before. I am so excited to learn how to self-instruction, goal-setting, self-monitoring, and self-reinforcement, which really benefit my writing (LGC interview).

\section{Conclusion and Discussion}

This case study aimed to apply the values-engaged approach to evaluate the impact of the Self-Regulated Strategy Development writing program (SRSDP) on the Grade 5 students, including the application of writing self-regulated strategy, writing motivation, and writing performance. Three findings found in this study.

Firstly, the SRSDP provided remarkable positive influences on lower-level and middle-level students' writing performance, such as improving their purposive sampling, structure, diction, and spelling, formatting, and punctuation. Besides, lower-level students explored that the SRSDP contributed the improvement of writing quality to them. This finding resembles that 
of previous studies (Graham, McKeown, Kiuhara \& Harris, 2012; Harris, Graham, \& Adkins, 2015; Harris \& Graham, 2009; Skibbe, Connor, Morrison, \& Jewkes, 2011) to some extent also support claims of Zimmerman (1998), in that SRL is an active and self-directed process. The writers can covert cognition, emotion, action, and situational context factors into academic skills. SRSD program in this study taught students to use self-regulation strategies focusing on goal setting, self-instruction, self-assessment and self-monitoring, and self-reinforcement, which is believed to be able of improving writing performance for lower-level and middle-level students.

Secondly, the SRSDP did not provide significant influences for three-level students' writing motivation. However, during the interview, lower-level students pinpointed that SRSDP enhanced their writing motivation. One of the reasons is probably because SRSD views learner as active collaborators. Instruction is tailored to children's needs and capabilities. Goals are adjusted to current performance for each student, students move through the instructional process at their own pace. These characteristics of SRSD teaching procedures could be contributed to enhancing lower-level students' learning motivation for writing in this case study.

Thirdly, the SRSDP provided significant influences on both of lower-level and middle-level students' application of writing self-regulated strategy. Besides, lower-level students agreed that SRSDP improved their writing skills, which brought more confidence to them. This finding resembles that of Jiang (2013) in that SRSD helped students to increase self-regulation strategies. One of the reasons is probably because SRSD is an on-going process in which new strategies are introduced and previously taught strategies are upgraded over time and insist that the instruction does not end until the student can use the strategy and self-regulation procedures efficiently and effectively, which could be considered the major reason to increase lower-level and middle-level students' mastery of application of the SRS in this case study.

However, this study also did not find SRSDP significantly contribute to higher-level students' writing performance, writing motivation, and application of the SRS. The reason could be that SRSD teaching model was originally designed to help the students with writing difficulties and clearly provided the students with problem-solving skills (Harris, Graham, \& Mason, 2006; Mason, Harris, \& Graham, 2011; Santangelo, Haris, \& Graham, 2008); therefore, the SRSDP did not provide remarkable impact on higher-level writing students.

\section{Acknowledgement}

The authors would like to thank the Ministry of Science and Technology, Taiwan for financially supporting this research under Contract No. MOST 106-2918-I-018 -002.

\section{References}

Amba, T. (2006). The practice of politics of responsive evaluation. American Journal of Evaluation, 27, 31-43. https://doi.org/10.1177/1098214005283189

Bakry, M. S., \& Alsamadani, H. A. (2015). Improving the persuasive essay writing of students of Arabic as a foreign language (AFL): Effects of self-regulated strategy 
development. Procedia-Social and Behavioral Sciences, 182, 89-97. https://doi.org/10.1016/j.sbspro.2015.04.742

Brandt, D. (1992). The cognitive as the social--An ethnomethodological approach to writing process research. Written Communication, 9(3), 315-351. https://doi.org/10.1177/0741088392009003001

Campbell, W. K., \& Campbell, S. M. (2009). On the self-regulatory dynamics created by the peculiar benefits and costs of narcissism: A contextual reinforcement model and examination of leadership. Self \& Identity, 8, 214-232. https://doi.org/10.1080/15298860802505129

Center for Psychological and Educational Testing Research and Development (2013). Criteria of writing test of basic academic competence for Junior high school students. Taipei, Taiwan: National Taiwan Normal University.

Christie, C. A., \& Alkin, M. C. (2008). Evaluation theory tree re-examined. Studies in Educational Evaluation, 34, 131-135. https://doi.org/10.1016/j.stueduc.2008.07.001

Everitt, A. (1996). Developing a critical evaluation. Evaluation, 2, 173-188. https://doi.org/10.1016/j.stueduc.2008.07.001

Festas, I., Oliveira, A., Rebelo, J., Damiao, M., Harris, K. \& Graham, S. (2015). Professional development in self-regulated strategy development : Effects on the writing performance of eighth grade Portuguese students. Contemporary Educational Psychology, 40, 17-27. https://doi.org/10.1016/j.cedpsych.2014.05.004

Fitzgerald, J. (2013). Struggling writers: Constructing their instruction: What and how. Annals of Dyslexia, 63, 80-95. https://doi.org/10.1007/s11881-011-0063-z

Flower, L. \& Hayes, J. R. (1981) A cognitive process theory of writing. College Composition and Communication, 32(4), 365-387. https://doi.org/10.2307/356600

Gao, W. Z. (2006). Analysis of Writing errors in sentences for elementary school students in Taiwan city (unpublished master's thesis). National Taichung University of Education, Taiwan.

Graham, S., \& Harris, K. (2003). Students with learning disabilities and the process of writing: A meta-analysis of RSD studies. In L. Swanson, K. Harris, \& S. Graham (Eds.), Handbook of research on learning disabilities (pp. 323-344). New York, NY: Guilford Press.

Graham, S., Harris, K. R., \& Mason, L. (2005). Improving the writing performance, knowledge, and motivation of struggling young writers: The effects of self-regulated strategy development. Contemporary Educational Psychology, 30, 207-241. https://doi.org/10.1016/j.cedpsych.2004.08.001

Graham, S., McKeown, D., Kiuhare, S., \& Harris, K. R. (2012). A meta-analysis of writing instruction for students in the elementary grades. Journal of Educational Psychology, 104, 879-896. https://doi.org/10.1037/a0029185

Greene, J. C., DeStefano, L., Burgon, H., \& Hall, J. (2006). An educative, values-engaged approach to evaluating STEM educational programs. New Directions for Evaluation, 109, 53-71. https://doi.org/10.1002/ev.178

Guba, E. G. \& Lincoln, Y. S. (1989). Fourth generation evaluation. Newbury Park, CA and London: Sage Publications. 
Hall, J. N., Greene, J. C., \& Ahn, J. (2012). Values-engagement in evaluation: Ideas, implications, and illustrations. American Journal of Evaluation, 33(2), 195-207. https://doi.org/10.1177/1098214011422592

Harris, K. R., Graham, S. \& Adkins, M., (2015). Practice-based professional development and self-regulated strategy development for Tier 2, at-risk writers in second grade. $\begin{array}{llll}\text { Contemporary } \quad \text { Educational } & \text { Psychology, } & \text { 40, }\end{array}$ https://doi.org/10.1016/j.cedpsych.2014.02.003

Harris, K. R., Graham, S., \& Mason, L. H. (2006). Improving the writing, knowledge, and motivation of struggling young writers: Effects of self-regulated strategy development with and without peer support. American Educational Research Journal, 43, 295-340. https://doi.org/10.3102/00028312043002295

Harris, K., \& Graham, S. (2009). Self-regulated strategy development in writing: Premises, evolution, and the future. British Journal of Educational Psychology, 6, 113-135. https://doi.org/10.1348/978185409X422542

Harris, K.R., \& Graham, S. (1996). Making the writing process work: Strategies for composition and self-regulation. Cambridge, MA: Brookline Books.

Hayes, J. (1996). A new framework for understanding cognition and affect in writing. In M. Levy \& S. Ransdell (Eds.), The science of writing: Theories, methods, individual differences, and applications (pp. 1-27). Mahwah, NJ: Erlbaum.

Hayes, J. R., \& Flower, L. S. (1983). Uncovering cognitive processes in writing: An introduction to protocol analysis. In P. Mosenthal, L. Tamor, and S. Walmsley (Eds.), Research on writing: Principles and Methods (pp. 207-220). New York: Longman.

Hillocks, G. (1984). What works in teaching composition: A meta-analysis of experimental treatment studies. American Journal of Education, 93 (1), 133-170. https://doi.org/10.1086/443789

House, E. R., \& Howe, K. R. (1999). Values in evaluation and social research. Thousand Oaks, CA: Sage.

Jiang, M. Y. (2013). The study on writing development and teaching effectiveness of self-regulated learning strategy (unpublished Ph.D. dissertation). National Chen Kung University, Tainan.

Mabry, L. (2010). Critical social theory evaluation: Slaying the dragon. New Directions for Evaluation, 127, 83-98. https://doi.org/10.1002/ev.341

Mason, L. H., Harris, K. R., \& Graham, S. (2011). Self-regulated strategy development for students with writing difficulties. Theory Into Practice, 50, 20-27. https://doi.org/10.1080/00405841.2011.534922

Santangelo, T., Harris, K. R. \& Graham, S. (2008). Using self-regulated strategy development to support students who have "trouble getting things into words", Remedial and Special Education, 29(2), 78-89. https://doi.org/10.1177/0741932507311636

Scriven, M. (2003). Evaluation in the new millennium: The transdisciplinary vision. In S. I. Donaldson \& M. Scriven (Eds.), Evaluating social programs and problems visions for the New Millennium (pp. 19-42). Mahwah, NJ: Lawrence Erlbaum. 


\section{Macrothink}

Journal of Studies in Education

ISSN 2162-6952 2018, Vol. 8, No. 2

Skibbe, L. E., Connor, C. M., Morrison, F. J., Jewkes, A. M. (2011). Schooling effects on preschoolers' self-regulation, early literacy, and language growth. Early Child Res Q., 26(1), 42-49. https://doi.org/10.1016/j.ecresq.2010.05.001

Stake, R. E. (2004). Standards-based and responsive evaluation. Thousand Oaks, CA: Sage. https://doi.org/10.4135/9781412985932

Wang, Y. P. (2009). A comparison study of self-regulated strategy development writing teaching and concept mapping writing teaching to improve the writing of self-regulation, writing performance, and writing motivation for sixth graders (unpublished master's thesis). National Pingtung University of Education, Pingtung, Taiwan.

Xu, Y. H., \& Yang, S. H. (2010). Detection and analysis of the fourth graders' narrative writing skills in central Taiwan. Education Records, 23, 37-82.

Yang, R. X. (2006). Sampling analysis of elementary schoolers' Grammar errors. In K. F. Wang \& L. G. Chen (eds.). Theory and practice of Chinese Writing. Taipei, Taiwan: Psychology Publication.

Zimmerman, B. J. (1986). Development of self-regulated learning: Which are the key $\begin{array}{llll}\text { sub-process. } \quad \text { Contemporary } & \text { Educational } & \text { Psychology, }\end{array}$ https://doi.org/10.1016/0361-476X(86)90027-5

\section{Copyright Disclaimer}

Copyright for this article is retained by the author(s), with first publication rights granted to the journal.

This is an open-access article distributed under the terms and conditions of the Creative Commons Attribution license (http://creativecommons.org/licenses/by/3.0/). 